Volume 03 Nomor 012021 : page 23-35 p-ISSN: 2686-262X e-ISSN : 2685-9300 DOI : 10.24256

\title{
Pengaruh Pendapatan Muslimah Bekerja Terhadap Kesejahteraan Ekonomi Keluarga (Studi Pada Madrasah Aliyah Negeri 2 Samarinda) \\ Tikawati $^{1}$, Hj. Norvadewi ${ }^{2}$, Raihanah $^{3}$ \\ 1,2,3 IAIN Samarinda \\ Jl. HM. Riffadin Loa Janan Ilir Kota Samarinda \\ E-mail: tika.ilir@gmail.com
}

\begin{abstract}
Abstrak
Wanita awalnya hanya dikaitkan tentang urusan di dalam rumah dan tidak bisa mengeksplore dengan bebas tentang hal-hal yang berada di luar rumah. Namun kemajuan jaman telah mengubah banyak pandangan tentang wanita. Kemudian karena adanya perkembangan jaman dan emansipasi, kini wanita memperoleh hak yang sama dengan laki-laki. Salah satunya wanita memiliki kesempatan untuk dapat memberikan kontribusi mengenai pendapatan pada keluarganya melalui perannya dengan bekerja di ranah publik. Karna saat ini semakin banyak wanita yang ikut berperan dalam dunia kerja guna meningkatkan kesejahteraan keluarganya dari sisi pendapatan. Tujuan dari penelitian ini untuk mengetahui pengaruh pendapatan muslimah bekerja terhadap kesejahteraan ekonomi keluarga. Hasil penelitia n menunjukkan bahwa kesejahteraan ekonomi keluarga (Y) dipengaruhi oleh pendapatan muslimah yang bekerja (X) sebesar 72,7\%, dan sisanya $(27,3 \%)$, dipengaruhi oleh faktor atau variabel lain di luar penelitian.
\end{abstract}

Kata Kunci : Emansipasi, Peranan, Wanita

\begin{abstract}
Abstact
Basically, women are only related to matters inside the house and can barely explore things to do outside. But time has changed a lot about women. Because of the changing stages of times and the emancipation, women today have the same rights as men. One of them is the woman who has the opportunity to be able to contribute income to the family through her role by working in the public sphere. Today more and more women are playing a role in the world of work to improve their welfare of their families. Hence, the purpose of this study was to observe the effect of Muslim women's income for their economic welfare. Based on the results of primary data processing that had been done, the coefficient of determination or) of 0.727 , meaning that the economic welfare of the family (Y) was influenced by the income of Muslim worker women $(\mathrm{X})$ of $72.7 \%$, and the rest $(27.3 \%)$, was influenced by factors or other variables outside the study.
\end{abstract}

Keywords : Emancipation, Role, Women 


\section{PENDAHULUAN}

Secara tradisional, wanita biasanya dikaitkan tentang hal-hal yang berkaitan dengan urusan rumah tangga saja. Ditambah pandangan masyarakat yang kebanyakan mengatakan bahwa tidak seharusnya wanita yang berada di luar rumah. Namun karena perkembangan zaman dan adanya emansipasi, ditambah adanya peningkatan latar belakang pendidikan kaum wanita itu sendiri yang mulai meningkat, pandangan yang menyatakan bahwa wanita hanyalah warga negara kelas dua mulai dapat diminimalisasikan (Susanto, 1997).

Ada banyak alasan mengapa wanita sekarang memilih untuk bekerja diluar. Tidak hanya karena tuntutan ekonomi, tetapi juga karena alasan-alasan lain seperti perbedaan latar belakang dan budaya, karena keinginan wanita itu sendiri untuk bekerja, ingin mengurangi perasaan stress karena menganggur dirumah, dan lain sebagainya. Sehingga hal inilah yang mengakibatkan peran wanita bervariasi, tidak lagi hanya sebagai wanita yang hanya berdiam diri dirumah mengurus segala keperluan rumah, akan tetapi juga bisa berkecimpung dalam berbagai hal yang lain (Pradhan, 2016).

Ditambah dalam Islam sendiri hukum wanita yang ingin bekerja juga mubah selama mendapatkan izin dari orangtuanya atau dari suaminya jika ia sudah menikah, tidak meninggalkan kewajibannya sebagai ibu dan istri bagi mereka yang sudah berumah tangga, serta dalam kondisi apapun baik saat bekerja atapun diluar rumah senantiasa menjaga kehormatannya (Wahid, 1999).

Melihat hal itu, saat ini telah banyak wanita yang kita lihat berkiprah di dunia kerja dan memiliki peran ganda dalam keluarga bagi mereka yang sudah menikah, yaitu tidak hanya berperan sebagai ibu rumah tangga yang mengurus dan mengatur segala urusan rumah tangga, namun juga ikut berperan dalam berbagai hal. Tetap saja, seorang wanita yang memiliki peran ganda dalam keluarganya, diharapkan untuk tetap bisa menyeimbangkan urusannya dengan baik, baik itu urusannya ketika di dalam rumah tangga, maupun dengan urusan di luar rumah tangganya (Ramadhan, 2016).

Adapun yang menjadi objek penelitiannya adalah guru-guru perempuan MAN 2 Samarinda yang berjumlah sebanyak 42 orang guru perempuan yang $100 \%$ beragama Islam disana dan jam kerja efektif adalah full, mulai dari pukul 07.15 WITA hingga 16.00 WITA, sehingga bisa dikatakan hampir semua wanita disana memiliki peran yang cukup besar dalam memenuhi kebutuhan ekonominya, ataupun mengatasi perekonomian keluarganya. Karena 
Volume 03 Nomor 012021 : page 23-35 p-ISSN: 2686-262X e-ISSN : 2685-9300 DOI : 10.24256

bukan hal yang tidak mungkin pendapatan mereka bisa jadi sama atau bahkan lebih tinggi daripada ayah atau saudara laki-lakinya bagi mereka yang belum menikah, dan lebih tinggi dari suami mereka jika mereka sudah menikah, namun besarnya pengaruh tersebut belum diketahui. Kurangnya penelitian dengan objek para guru juga menjadi alasan yang menyebabkan peneliti ingin melakukan penelitian lebih lanjut mengenai profesi guru yang ingin diketahui pengaruh pendapatannya dengan judul "Pengaruh Pendapatan Muslimah Bekerja terhadap Kesejahteraan Ekonomi Keluarga (Studi Kasus pada Guru-Guru MAN 2 Samarinda)”. Dengan hipotesis yaitu: $\mathrm{H}_{0}$ : Tidak terdapat pengaruh yang signifikan antara pendapatan muslimah bekerja dengan kesejahteraan ekonomi keluarga. Dan Ha: Terdapat pengaruh yang signifikan antara pendapatan muslimah bekerja dengan kesejahteraan ekonomi keluarga.

\section{TINJAUAN TEORISTIK}

\section{Madrasah Aliyah Negeri 2 Samarinda}

Madrasah Aliyah Negeri (MAN) 2 Samarinda adalah sekolah menengah setara SMA yang bercirikan Agama Islam. Madrasah ini berlokasi di Jalan Harmonika No 98 Samarinda dan masuk sebagai salah satu MAN unggulan di Indonesia. Madrasah Aliyah Negeri 2 Samarinda senantiasa tiap tahunnya berupaya agar adanya peningkatan kualitas pelayanan dan pelaksanaan pendidikan, sehingga predikat sebagai MAN yang unggul dan favorit di Provinsi Kalimantan Timur. Hal ini terlihat dari beberapa prestasi yang tercapai dibidang akademik dan non akademik yang terdapat pada Profile MAN 2 Samarinda.

Mengenai guru-guru di Madrasah Aliyah Negeri 2 Samarinda, jam kerja adalah full, yaitu mulai hari Senin-Sabtu, dengan jam kerja pada hari Senin-Jumat dari pukul 07.15 WITA sampai dengan 16.00 WITA, dan pada hari sabtu mulai dari pukul 07.00 WITA sampai dengan setelah solat zuhur (Profile MAN 2 Samarinda). Sedangkan jumlah guru yang ada di MAN 2 Samarinda bisa dilihat pada tabel 1 sebgai berikut:

Tabel 1. Jumlah berdasarkan genjer dan pendidikan

\begin{tabular}{|c|l|c|c|}
\hline No & \multicolumn{1}{|c|}{ Rekapitulasi } & Jumlah Guru & Total \\
\hline 1 & Guru laki-laki & 25 & 25 \\
\hline 2 & Guru perempuan & 46 & 46 \\
\hline 3 & Sarjana/S1 & 47 & 47 \\
\hline
\end{tabular}




\begin{tabular}{|c|l|c|c|}
\hline 4 & Pasca sarjana/S2 & 24 & 24 \\
\hline
\end{tabular}

Sumber : Profile MAN 2 Samarinda

\section{Pendapatan}

\section{a. Pengertian Pendapatan Keluarga}

Pendapatan adalah dana yang diterima dari hasil investasi, sesuatu yang memiliki

nilai ekonomi dari hasil suatu aktivitas ekonomi dan biasanya berbentuk uang (Heryanti, 2017).

\section{b. Sumber Penerimaan Pendapatan Rumah Tangga}

Setiap pendapatan dan penerimaan yang diperoleh dari seluruh anggota keluarga dari aktivitas ekonomi, diantaranya yaitu:

1) Penerimaan dari gaji atau upah yang diterima oleh seluruh anggota rumah tangga ekonomi yang bekerja.

2) Penerimaan dari laba bersih atas hasil usaha yang dijalankan oleh anggota keluarga.

3) Penerimaan lainya yaitu penerimaan selain gaji atau upah (Kurniawati, 2015).

\section{Kesejahteraan Keluarga}

Kesejahteraan merupakan suatu kondisi dimana seseorang menuju pada suatu keadaan yang lebih baik, lebih makmur, damai, sehat, dan terpenuhinya berbagai macam kebutuhan, baik dari segi pemenuhan kebutuhan spiritual, maupun kebutuhan material (Khiyaroh, 2017).

\section{Kaitan antara Pendapatan dan Kesejahteraan}

Tiap-tiap manusia tentunya membutuhkan harta, karena dengan hartalah manusia bisa menggunakannya untuk memenuhi kebutuhan hidupnya sehari-hari. Adapun salah satu cara memperoleh harta adalah dengan bekerja. Jika seseorang memperoleh pendapatan dari hasilnya bekerja, maka pendapatan itulah yang nantinya akan ia gunakan untuk memenuhi kebutuhan hidupnya. Semakin tinggi tingkat pendapatannya, maka akan semakin banyak pula kebutuhan yang bisa ia penuhi. Jika semakin banyak kebutuhan yang bisa ia penuhi, itu artinya akan semakin dekat pula ia untuk mencapai kesejahteraannya (Rosyidi, 2009)

\section{METODE PENELITIAN}


Volume 03 Nomor 012021 : page 23-35 p-ISSN: 2686-262X e-ISSN : 2685-9300

Penelitian ini menggunakan teknik pengumpulan data dengan observasi, wawancara, dan kuisioner pada guru-guru Muslimah di MAN 2 Samarinda sebanyak 42 orang. Metode analisis datanya yaitu mengukur kualitas data dengan uji kualitas data (validitas dan reliabilitas), uji asumsi klasik (Teguh, 2008) dengan menggunakan aplikasi SPSS dan analisis regresi sederhana model yang digunakan adalah : $\mathrm{Y}=\mathrm{a}+\mathrm{bX}+\in$ (Sulliyanto (2011)

\section{HASIL PENELITIAN DAN PEMBAHASAN}

Hasil

\section{Uji Validitas}

Hasil uji validitas pada variabel pendapatan dan uji valididatas pada variabel kesejahteraan ekonomi keluarga dapat lihat pada tabel 2 dan tabel 3 dibawah ini:

Tabel 2. Hasil Uji Validitas Variabel Pendapatan

\begin{tabular}{|c|c|c|c|}
\hline Butir Soal & R hitung & R tabel & Keterangan \\
\hline 1 & 0,728 & 0,304 & $\begin{array}{c}\text { VALID } \\
0,728>0,3044\end{array}$ \\
\hline 2 & 0,465 & 0,304 & $\begin{array}{c}\text { VALID } \\
0,465>0,3044\end{array}$ \\
\hline 3 & 0,798 & 0,304 & $\begin{array}{c}\text { VALID } \\
0,798>0,3044\end{array}$ \\
\hline 4 & 0,838 & 0,304 & $\begin{array}{c}\text { VALID } \\
0,838>0,3044\end{array}$ \\
\hline 5 & 0,789 & 0,304 & $\begin{array}{c}\text { VALID } \\
0,789>0,3044\end{array}$ \\
\hline 6 & 0,852 & 0,304 & $\begin{array}{c}\text { VALID } \\
0,852>0,3044\end{array}$ \\
\hline 7 & 0,805 & 0,304 & $\begin{array}{c}\text { VALID } \\
0,805>0,3044\end{array}$ \\
\hline
\end{tabular}

Sumber: Pengolahan Data Primer Hasil Penelitian, 2020

Berdasarkan tabel 2 uji validitas variabel pendapatan diatas, dapat terlihat bahwa dari seluruh butir soal untuk variabel pendapatan guru-guru perempuan bekerja menunjukkan hasil yang valid. Hal tersebut dapat terlihat memberikan hasil yang positif dan semua nilai yang ditunjukkan yaitu $\mathrm{R}$ hitung $>\mathrm{R}$ tabel $(0,304)$.

Tabel 3. Hasil Uji Validitas Variabel Kesejahteraan Ekonomi Keluarga

\begin{tabular}{|c|c|c|c|}
\hline $\begin{array}{r}\text { Butir } \\
\text { Soal }\end{array}$ & R hitung & $\mathrm{R}$ tabel & Keterangan \\
\hline 1 & 0,871 & 0,304 & VALID \\
\hline
\end{tabular}




\begin{tabular}{|c|c|c|c|} 
& & & $0,871>0,3044$ \\
\hline 2 & 0,824 & 0,304 & $\begin{array}{c}\text { VALID } \\
0,824>0,3044\end{array}$ \\
\hline 3 & 0,804 & 0,304 & $\begin{array}{c}\text { VALID } \\
0,804>0,3044\end{array}$ \\
\hline 4 & 0,748 & 0,304 & $\begin{array}{c}\text { VALID } \\
0,748>0,3044\end{array}$ \\
\hline 5 & 0,833 & 0,304 & $\begin{array}{c}\text { VALID } \\
0,833>0,3044\end{array}$ \\
\hline 6 & 0,734 & 0,304 & $\begin{array}{c}\text { VALID } \\
0,734>0,3044\end{array}$ \\
\hline 7 & 0,498 & 0,304 & $\begin{array}{c}\text { VALID } \\
0,498>0,3044\end{array}$ \\
\hline 8 & 0,681 & 0,304 & $\begin{array}{c}\text { VALID } \\
0,681>0,3044\end{array}$ \\
\hline 9 & 0,773 & 0,304 & $\begin{array}{c}\text { VALID } \\
0,773>0,3044\end{array}$ \\
\hline 10 & 0,882 & 0,304 & $\begin{array}{c}\text { VALID } \\
0,882>0,3044\end{array}$ \\
\hline
\end{tabular}

Sumber: Pengolahan Data Primer Hasil Penelitian, 2020

Berdasarkan tabel 3 hasil uji validitas variabel kesejahteraan ekonomi keluarga diatas, dapat terlihat bahwa semua butir soal variabel kesejahteraan ekonomi keluarga dari guruguru perempuan yang bekerja kesemuanya menunjukan hasil yang valid. Hal tersebut terlihat semua nilai memberikan hasil yang positif dan semua nilai ditunjukkan yaitu $\mathrm{R}$ hitung $>\mathrm{R}$ tabel $(0,304)$.

\section{Uji Reliabilitas}

Hasil uji reliabilitas pada penelitian ini dapat dilihat pada tabel 4 dibawah ini:

Tabel 4. Hasil Uji Reliabilitas

\begin{tabular}{|c|c|c|c|c|}
\hline No & Variabel & $\begin{array}{c}\text { Croanbach } \\
\text { 's Alpha }\end{array}$ & $\begin{array}{c}\text { Croanbach's } \\
\text { Alpha yang } \\
\text { diisyaratkan }\end{array}$ & Keterangan \\
\hline 1 & Pendapatan & 0,858 & 0,6 & $\begin{array}{c}\text { RELIABLE } \\
0,734>0,6\end{array}$ \\
\hline 2 & $\begin{array}{c}\text { Kesejahteraan } \\
\text { Ekonomi } \\
\text { Keluarga }\end{array}$ & 0,920 & 0,6 & $\begin{array}{c}\text { RELIABLE } \\
0,920>0,6\end{array}$ \\
\hline
\end{tabular}

Sumber: Pengolahan Data Primer Hasil Penelitian, 2020. 
Volume 03 Nomor 012021 : page 23-35 p-ISSN: 2686-262X e-ISSN : 2685-9300

Bedasarkan tabel IV hasil uji reliabilitas di atas menunjukkan semua variabel dinyatakan reliable dengan hasil variabel pendapatan bernilai 0,858 lebih esar dari 0,6 dan pada variabel kesejahteraan ekonomi keluarga bernilai 0,920 juga lebih besar dari 0,6. Sehingga dapat disimpulkan bahwa instrument dalam kuisioner penelitian kali ini reliabel dan memenuhi syarat.

\section{Uji Asumsi Klasik}

a. Uji Normalitas

Pada penelitian ini didapat hasil uji normalitas pada tabel 5 sebagai berikut:

\section{Tabel 5. Hasil Uji Normalitas}

\begin{tabular}{|c|c|c|c|c|c|c|}
\hline \multicolumn{7}{|c|}{ Tests of Normality } \\
\hline & \multicolumn{3}{|c|}{ Kolmogorov-Smirnov ${ }^{\mathrm{a}}$} & \multicolumn{3}{|c|}{ Shapiro-Wilk } \\
\hline & Statistic & $\mathrm{df}$ & Sig. & Stattist & df & Sig. \\
\hline $\begin{array}{l}\text { Unstandardized } \\
\text { Residual }\end{array}$ & .203 & 42 & .000 & .951 & 42 & .071 \\
\hline
\end{tabular}

a. Liliiiefors Significance Correction.

Sumber: Pengolahan Data Primer Hasil Penelitian, 2020.

Berdasarkan tabel 5 hasil uji normalitas output yang ditunjukkan signifikan dari variabel pendapatan dan kesejahteraan ekonomi keluarga. Terlihat nilai Sig. 0,071>0,05, maka sebagaimana dasar pengambilan keputusan dalam uji normalitas shapiro wilk diatas, dapat ditarik kesimpulan bahwa data berdistribusi normal.

b. Uji Heteroskedastisitas

Pada penelitian ini didapatkan hasil uji heteroskedastisitas yang bisa dilihat pada gambar 1 sebagai berikut:

\section{Gambar 1. Uji Heteroskedastisitas}

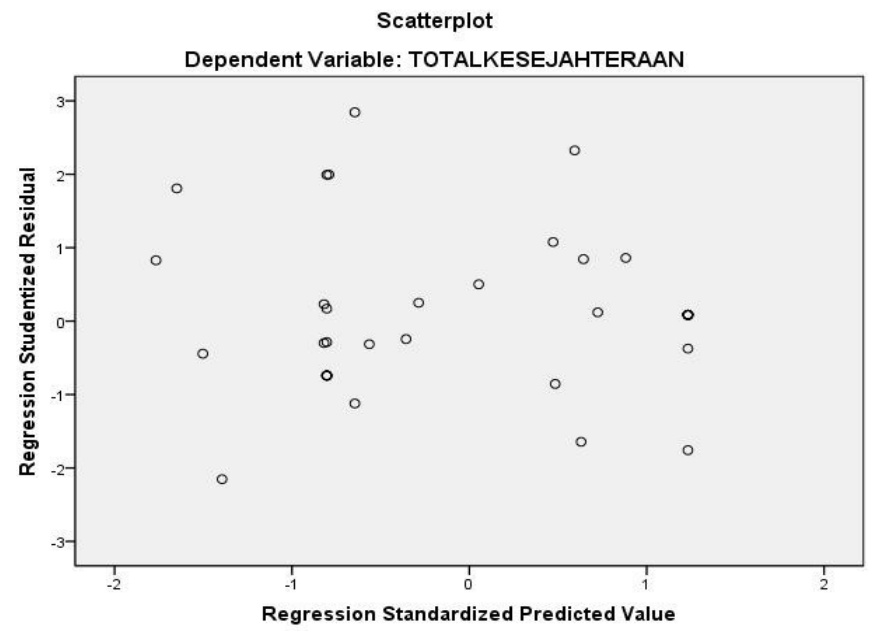


Sumber : Pengolahan Hasil Data Primer, 2020.

Berdasarkan pada gambar 1 hasil uji heteroskedastisitas diatas dapat diketahui bahwa plot tersebar dengan acak baik diatas maupun dibawah angka nol pada sumbu Reression Studentized Residual. Sehingga berdasarkan atas dasar pengambilan keputusan Uji Heteroskedastisitas di atas dapat ditarik kesimpulan bahwa pada model regresi yang dibentuk dinyatakan tidak terjadi gejala heteroskedastisitas.

c. Uji Autokorelasi

Pada penelitian ini peroleh hasil uji autokorelasi yang bisa dilihat pada tabel 6 dibawah ini:

Tabel 6. Hasil Uji Autokorelasi Model Summary ${ }^{\text {b }}$

\begin{tabular}{|l|l|r|r|r|r|}
\hline Model & \multicolumn{1}{|c|}{ R } & \multicolumn{1}{c|}{$\begin{array}{c}\cdot \\
\text { R Square }\end{array}$} & $\begin{array}{c}\cdot \cdot \\
\text { Square }\end{array}$ & $\begin{array}{c}\text { Durbin - } \\
\text { Std. Error of the } \\
\text { Estimate }\end{array}$ & \\
\hline 1 & $.852^{\mathrm{a}}$ & .727 & .720 & 2.38953 & 2.211 \\
\hline
\end{tabular}

a. Predictors: (Constant), Total Pendapatan b. Dependent Variable: Total Kesejahteraan Sumber: Pengolahan Data Primer Hasil Penelitian, 2020

Berdasarkan tabel 6 hasil uji autokorelasi output di atas dapat dilihat bahwa nilai Durbin Watson (DW) sebesar 2,211. Adapun nilai Sig adalah sesesar 0,005 dengan jumlah data $(n)=42$, serta $k=1$ (jumlah variabel bebas), diperoleh nilai $\mathrm{dL}$ sebesar 1,4421 dan dU sebesar 1,5444. Karena nilai Durbin Watson lebih besar dari batas dU dan kurang dari dU $(4-\mathrm{dU})=4-1,5444=2,4556$. Maka didapat kesimpulan yaitu tidak diperoleh autokorelasi.

\section{Uji Hipotesis}

a. Uji t (parsial)

Pada penelitian ini dihasilkan uji t yang bisa dilihat pada tabel 7 dibawah ini:

\section{Tabel 7. Hasil Uji t (Parsial)}

Coefficients $^{\mathbf{a}}$

\begin{tabular}{|l|c|c|c|}
\hline & $\begin{array}{c}\text { Unstandardized } \\
\text { Coefficients }\end{array}$ & $\begin{array}{c}\text { Standardized } \\
\text { Coefficients }\end{array}$ &
\end{tabular}


Volume 03 Nomor 012021 : page 23-35 p-ISSN: 2686-262X e-ISSN : 2685-9300

\begin{tabular}{|c|c|c|c|c|c|}
\hline Model & B & Std. Error & Beta & $\mathrm{t}$ & Sig. \\
\hline $1 \quad$ (Constant) & 7.063 & 3.685 & & 1.917 & .062 \\
\hline Total Pendapatan & 1.226 & .119 & .852 & 10.308 & .000 \\
\hline
\end{tabular}

a. Dependent Variable: Total Kesejahteraan

Sumber: Pengolahan Data Primer Hasil Penelitian, 2020.

Berdasarkan tabel 7 hasil uji t (Parsial) output diatas, dapat diketahui bahwa variabel pendapatan memiliki nilai signifikansi 0,00 di mana nilai signifikan dari variabel pendapatan lebih kecil dari 0,05 artinya variabel pendapatan secara parsial berpengaruh positif yang signifikan terhadap kesejahteraan ekonomi keluarga.

Adapun dasar pengambilan keputusan pada uji t sebagai berikut :

Pada variabel pendapatan didapat nilai t $10,308>2,021$, maka $\mathrm{H}_{0}$ ditolak dan $\mathrm{H}_{1}$ diterima, artinya variabel pendapatan berpengaruh signifikan terhadap variabel kesejahteraan ekonomi keluarga.

\section{b. Uji Koefisien Determinasi}

Pada penelitian ini dihasilkan uji koefisien determinasi yang bisa dilihat pada tabel 8 dibawah ini:

Tabel 8. Hasil Uji Koefisien Determinasi Model Summary

\begin{tabular}{|c|c|c|c|c|}
\hline Model & $\mathrm{R}$ & R Square & $\begin{array}{l}\text { Adjusted R } \\
\text { Square }\end{array}$ & $\begin{array}{l}\text { Std. Error of the } \\
\text { Estimate }\end{array}$ \\
\hline 1 & $852^{\mathrm{a}}$ & .727 & .720 & 2.38953 \\
\hline
\end{tabular}

a. Predictors: (Constant), Total Pendapatan

Sumber: Pengolahan Data Primer Hasil Penelitian, 2020

Bedasarkan tabel 8 hasil uji koefisien determinasi ouput dari SPSS "Model Summary" diatas, diketahui nilai koefisien determinasi atau R square adalah 0,727. Nilai R Square ini 
asalnya dari pengkuadratan nilai koefisien kolarasi atau $\mathrm{R}$, yaitu sebesar $0,852 \times 0,852=$ 0,727. Sehingga, jika besar angka koefisien determinasi (R square) adalah 0,727 atau 72,7\%, maka dapat ditarik kesimpulan bahwa variabel pendapatan (X) berpengaruh terhadap variabel kesejahteraan ekonomi keluarga (Y) sebesar 72,7\%. Sedangkan sisanya (100\% $72,7 \%=27,3 \%$ ) dipengaruhi oleh variabel yang lain diluar persamaan regresi ini atau variabel yang tidak diteliti.

\section{Analisis Regresi Sederhana}

Pada penelitian ini dihasilkan nilai regresi sederhana yang bisa dilihat pada tabel 9 dibawah ini:

Tabel 9. Hasil Analisa Regresi Sederhana

\begin{tabular}{|c|c|c|c|c|c|}
\hline \multicolumn{6}{|c|}{ Coefficients $^{\mathrm{a}}$} \\
\hline \multirow[b]{2}{*}{ Model } & \multicolumn{2}{|c|}{$\begin{array}{l}\text { Unstandardized } \\
\text { Coefficients }\end{array}$} & \multirow{2}{*}{$\begin{array}{c}\text { Standardized } \\
\text { Coefficients } \\
\text { Beta } \\
\end{array}$} & \multirow[b]{2}{*}{$\mathrm{t}$} & \multirow[b]{2}{*}{ Sig. } \\
\hline & $\mathrm{B}$ & Std. Error & & & \\
\hline (Constant) & 7.063 & 3.685 & & 1.917 & .062 \\
\hline Total Pendapatan & 1.226 & .119 & .852 & 10.308 & .000 \\
\hline
\end{tabular}

a. Dependent Variable: Total Kesejahteraan

Sumber: Pengolahan Data Primer Hasil Penelitian, 2020.

Berdasarkan tabel 9 hasil analisa regresi sederhana "Coefficients" dengan alat bantu aplikasi SPSS di atas, dapat diketahui bahwa:

a. Nilai konstanta didapat sebesar 7,063. Angka ini merupakan angka konstan yang berarti jika tidak ada variabel Pendapatan (X), maka nilai Kesejahteraan Ekonomi Keluarga (Y) adalah sebesar 7,063.

b. Nilai koefisien regresi didapat sebesar 1,226 yang mengandung arti bahwa setiap penambahan $1 \%$ tingkat pendapatan maka kesejahteraan ekonomi keluarga akan meningkat sebesar 1,226.

c. Dari pengambilan keputusan di atas dapat dikatakan bahwa pendapatan (X) berpengaruh positif terhadap kesejahteraan ekonomi keluarga (Y). Sehingga persamaan regresinya adalah $\mathrm{Y}=7,063+1,226 \mathrm{X}$.

\section{Pembahasan}


Volume 03 Nomor 012021 : page 23-35 p-ISSN: 2686-262X e-ISSN : 2685-9300 DOI : 10.24256

Dalam pembahasan ini peneliti akan menguraikan fakta-fakta yang sudah di analisis untuk menjawab rumusan masalah "Apakah pendapatan muslimah bekerja berpengaruh signifikan terhadap kesejahteraan ekonomi keluarga?"

Untuk melihat bagaimana signifikan atau tidaknya suatu pengaruh variabel, dapat dilihat dari uji t, yaitu variabel pendapatan memiliki nilai signifikan 0,000 dimana nilai signifikan dari variabel pendapatan lebih kecil dari 0,05 artinya variabel pendapatan secara parsial berpengaruh signifikan positif terhadap kesejahteraan ekonomi keluarga. Selain itu ada pada variabel pendapatan yaitu nilai $t$ hitung $>t$ tabel $(10,308>2,021)$, sehingga $\mathrm{H}_{0}$ ditolak dan $\mathrm{H}_{1}$ diterima yang berarti variabel pendapatan memiliki pengaruh yang signifikan terhadap variabel kesejahteraan ekonomi keluarga.

Kemudian untuk mengetahui besarnya pengaruh variabel independent terhadap variabel dependen, maka hal ini dapat dilihat atau diwakili oleh besarnya nilai dari koefisien determinasi. Berdasarkan hasil pengolaha $\mathrm{n}$ data primer yang telah dilakukan, maka nilai koefisien determinasi sebesar 0,727, artinya kesejahteraan ekonomi keluarga (Y) dipengaruhi oleh pendapatan muslimah yang bekerja (X) sejumlah $72,7 \%$ dan sisanya sejumlah $27,3 \%$ terpengaruhi oleh faktor variabel lain di luar penelitian.

Pendapatan yang telah didapatkan dari wanita yang bekerja, menunjukkan bahwa pendapatan tersebut mampu memberika $\mathrm{n}$ dampak/efek terhadap kesejahteraan ekonomi keluarga, menjadi nilai tambah. Bagaimana pendapatan yang telah diterima semaksimal mungk in tersebut mampu menunjang kebutuhan hidup yang pada akhirnya dapat menentukan tercapai atau tidaknya kesejahteraan keluarga (Christoper, 2017).

Kesejahteraan keluarga sendiri adalah tercapainya suatu kondisi pada suatu keadaan yang baik, kondisi dimana setiap orang yang ada di dalamnya berada dalam kondisi yang makmur, sehat, dan damai. Sesorang yang hidup tidak mengalami kemiskinan, kelaparan, dan ketakutan maka hidupnya aman dan tentram lahir dan batin (Purwanto, 2018). Penelitian ini sejalan dengan penelitian yang telah peneliti tulis dikajian pustaka pada skripsi Heryanti (2017) yang menyatakan bahwa pendapatan istri mampu berpengaruh secara signifikan terhadap kesejahteraan ekonomi keluarga.

\section{KESIMPULAN}


Berdasarkan hasil analisis data dengan SPSS versi 19, pengujian hipotesis pendapatan secara parsial diperoleh nilai $t$ hitung $>t$ tabel $(10,308>2,021)$, maka $\mathrm{H}_{0}$ ditolak dan $\mathrm{H}_{1}$ diterima artinya variabel pendapatan berpengaruh signifikan terhadap variabel kesejahteraan ekonomi keluarga. Adapun nilai koefisien determinasi sebesar 0,727, mempunyai arti bahwa kesejahteraan ekonomi keluarga (Y) yang dipengaruhi oleh pendapatan muslimah yang bekerja (X) bernilai sejumlah $72,7 \%$ dan sisanya sejumlah $27,3 \%$, berarti ada pengaruh variabel lainya di luar penelitian. Selain itu, persamaan regresi yang diperoleh dari penelitian adalah $\mathrm{Y}=7,063+1,226 \mathrm{X}$. Bahwa besarnya pengaruh pendapatan muslimah yang bekerja $(\mathrm{X})$ terhadap kesejahteraan ekonomi keluarga (Y) adalah Rp 1,226 (tiap-tiap ada tambahan Rp 1 dari pendapatan muslimah yang bekerja).

\section{Saran}

Bagi para muslimah yang telah bekerja, hendaknya mampu untuk selalu mengelola pendapatan yang telah ia peroleh sebaik mungkin. Bagaima na pendapatan yang telah di dapat mampu menutupi kebutuhan hidup keluarga dengan mengatur keuangan sesuai dengan kebutuhan realnya. Namun juga dengan tidak melupakan bahwa tidak semua uang yang diperoleh harus semuanya dihabiskan, melainkan bagaimana uang tersebut juga dapat disimpan untuk jaga-jaga kalau ada kebutuhan mendadak di masa depan.

\section{DAFTAR PUSTAKA}

Heryanti, "Pengaruh Pendapatan Istri terhadap Kesejahteraan Ekonomi Keluarga Menurut Perspeksi Ekonomi Islam'. Skripsi, IAIN Sultan Maulana Hasanuddin Banten tahun 2017.

Khiyaroh, Intihaul, Menggapai Kesejahteraan Keluarga, Cetakan Pertama, Yogyakarta: Darul Hikmah, 2017.

Kurniawati, Titiek, “Tingkat Kesejahteraan Pengrajin Bambu di Desa Sendari Kecamatan Mlati Kabupaten Sleman Daerah Istimewa Yogyakarta”, Skripsi Universitas Negeri Yogyakarta tahun 2015.

Pradhan, Gayatri, Work Life Balance among Working Women-A Cross Cultural Review, Working Paper, Institute for Social and Economic Change (ISEC) 2016.

Ramadhan, Dianti, Peningkatan Kesejahteraan Ekonomi Keluarga Melalui Usaha Kerajinan Tangan Khas Lampung dalam Perspektif Ekonomi Islam, Skripsi, FEBI IAIN Raden Intan Lampung, tahun 2016 
Volume 03 Nomor 012021 : page 23-35

p-ISSN: 2686-262X e-ISSN : 2685-9300

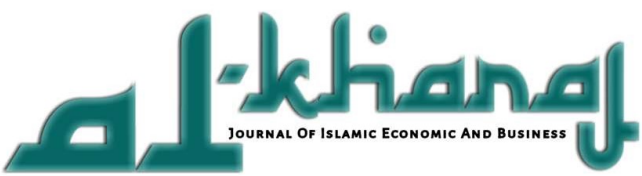

DOI : 10.24256

Rosyidi, Suherman, Pengantar Teori Ekonomi: Pendekatan Kepada Teori Ekonomi Mikro \& Makro, Jakarta Press, 2009.

Sugiyono, Metode Penelitian Bisnis, Cetakan Ketiga, Bandung: Alfabeta, 2017. Sulliyanto, Ekonometrika Terapan - Teori dan Aplikasi dengan SPSS, Yogyakarta: ANDI, 2011.

Susanto, A. B Wanita Masa Kini Pribadi Mempesona Penunjang Kesuksesan, Cetakan Pertama, Jakarta: PERUM Percetakan Negara RI, 1997.

Teguh, Cara Mudah Melakukan Analisa Statistik dengan SPSS, Cetakan Pertama, Yogyakarta: Gaya Media, 2008.

Wahid, Abdurrahman, et.al, Menakar Harga Perempuan, Cetakan Kedua, Bandung: Mizan, 1999. 
Volume 03 Nomor 012021 : page 23-35 p-ISSN: 2686-262X e-ISSN : 2685-9300

DOI : 10.24256 